\title{
Uma análise crítica da competência cultura digital na Base Nacional Curricular Comum
}

\author{
A critical analysis of the digital culture in the \\ Common National Curriculum Base
}

Aline Alvares Machado'

DMarília Abrahão Amaral ${ }^{1}$

\begin{abstract}
'Universidade Tecnológica Federal do Paraná (UTFPR), Programa de Pós-Graduação em Tecnologia e Sociedade, Curitiba, PR, Brasil.

Autora correspondente: alinebio01@gmail.com
\end{abstract}

Resumo: O papel das novas tecnologias não pode ser indiscutível, cabendo à sociedade o debate sobre as apropriações, significados e importância desses artefatos. No âmbito da Educação, a Base Nacional Comum Curricular (BNCC) estabelece competências para a composição dos currículos brasileiros e especifica a competência em Cultura Digital como um dos conjuntos de habilidades e conhecimentos a serem mobilizados em todas as disciplinas do Ensino Fundamental. Neste artigo, a Cultura Digital na BNCC será analisada pelo olhar da Filosofia Crítica da Tecnologia e de pedagogias críticas. Conclui-se que o texto da Competência Cultura Digital na BNCC carece de uma visão crítica de tecnologia, em que esta deixe de ser uma coleção de objetos e técnicas, e seja percebida como um produto das interações sociais. Essa concepção crítica pode auxiliar os docentes na construção de uma base cultural e técnica para os educandos.

Palavras-chave: BNCC; Formação de competências; Cultura digital; Tecnologia educacional; Pedagogia crítica.

Abstract: The role of new technologies cannot be undisputed, and society has to debate the appropriations, meanings and importance of these artifacts. In the field of Education, the National Common Curricular Base (BNCC) establishes competencies for the composition of Brazilian curricula and specifies the Digital Culture as one of the sets of skills and knowledge to be mobilized in all subjects of Elementary Education. In this article, Digital Culture at BNCC will be analyzed from the perspective of Critical Philosophy of Technology and critical pedagogies. It is concluded that the text of the Digital Culture Competence at BNCC lacks a critical view of technology, in which this is no longer a collection of objects and techniques, but it is perceived as a product of social interactions. This critical conception can assist teachers in building a cultural and technical basis for students.

Keywords: BNCC; Literacy training; Digital culture; Educational technology; Critical pedagogy.

Recebido em: 25/09/2020

Aprovado em: 22/02/2021 


\section{Introdução}

A Base Nacional Comum Curricular (BNCC) é o resultado da discussão promovida pelo Conselho Nacional da Educação e pelo Ministério da Educação, a partir da Lei de Diretrizes e Bases da Educação (LDB) de 1996 que, no artigo 26, determina a construção de uma base nacional comum para os currículos da Educação Infantil e dos Ensinos Fundamental e Médio (BRASIL, 1996). A responsabilidade da União em estabelecer tal base é destacada no artigo $9^{\circ}$ da LDB (BRASIL, 1996), mas, mesmo assim, a base começou a ser discutida e organizada apenas em 2014, ou seja, 18 anos depois do estabelecimento desse critério, e as versões finais somente foram homologadas em 2017 (Educação Infantil e Ensino Fundamental) e 2018 (Ensino Médio) (BRASIL, 2020).

A proposta de uma Cultura Digital associada diretamente às bases de uma educação nacional gerou a necessidade de criar uma Competência na BNCC, com esse nome. A inclusão da Competência Cultura Digital na BNCC, portanto, inclui interpretações e apropriações das tecnologias que são inerentes aos grupos que participaram ativamente de sua construção e aos seus contextos sociais e históricos. Por isso, se entende que uma leitura consciente e reflexiva da BNCC é necessária, leitura esta que se aproxima de uma análise do conteúdo (BARDIN, 1977).

A análise do conteúdo, segundo Bardin (1977), tem caráter essencialmente crítico, fomentando uma pesquisa de natureza qualitativa e que se alinha com a ruptura de padrões estabelecidos.

A partir disso, visando a escapar da leitura simples e mecânica, buscou-se uma interpretação da Competência Cultura Digital na BNCC por meio da Teoria Crítica da Tecnologia (FEENBERG, 2017). Para Feenberg (2017), os sistemas sociais tecnocráticos são aqueles que valorizam excessivamente o papel da racionalidade e da eficiência como critério de seleção das ações e das políticas públicas, desconsiderando, ou atribuindo valor muito menor aos grupos sociais na construção e interpretação dos artefatos tecnológicos. À vista disso, o papel das tecnologias nos grupos sociais deve ser pauta de discussão, cabendo aos diferentes grupos sociais os processos de atribuição de significado e importância dessas tecnologias em seus diferentes locais de uso e apropriação.

Entende-se que essa discussão crítica acerca dos artefatos tecnológicos, embora mais intensa no campo teórico, deve se refletir nas escolhas e nas práticas docentes. Nesse sentido, se adota a visão de Dermeval Saviani (SAVIANI, 2012a), que compreende que a Educação é campo de disputas e que o fazer do/a professor/a, ou seja, a sua prática pedagógica, deve ser crítica e situada.

Assim como no caso das escolhas técnicas feitas no campo das tecnologias, Saviani (2012b) é categórico ao afirmar que os conhecimentos ensinados na escola não são neutros, mas, ao contrário, são escolhidos e ensinados para satisfazer necessidades específicas. Segundo ele, "[...] os interesses impelem os conhecimentos e, ao mesmo tempo, os circunscrevem dentro de determinados limites" (SAVIANI, 2012b, p. 66).

Ainda no sentido de valorizar a ação pedagógica na apropriação crítica dos conhecimentos e, neste caso em especial, das tecnologias, ressalta-se a obra de Paulo Freire (FREIRE, 2002), na qual se destaca que o fazer do/a professor/a, numa concepção democrática de ensinar e de aprender, passa pela crítica dos objetos do conhecimento como forma de desenvolver sua autonomia e sua liberdade de pensamento. 
Freire (2002) define essa postura crítica como uma necessidade de "[...] não estarmos demasiadamente certos de nossas certezas" (FREIRE, 2002, p. 14). Assim, não há a possibilidade de ser um/a professor/a crítico/a sem exercitar a leitura crítica daquilo que se ensina, o que resulta numa Educação mais questionadora quanto à sua realidade imediata, mas também quanto à real necessidade de desenvolver determinadas habilidades ou práticas.

Dessa forma, entendeu-se que a articulação entre as teorias críticas dos campos da Educação e da Tecnologia pode proporcionar uma boa compreensão das tecnologias digitais no contexto social atual e na práxis pedagógica. Este artigo se propõe a estabelecer diálogos entre a Cultura Digital, uma das dez Competências Gerais da BNCC para o Ensino Fundamental e Médio, a teoria crítica da tecnologia de Feenberg $(1999,2017)$ e as pedagogias críticas de Freire $(1994,2002)$ e Saviani (2012a, 2012b), por meio da análise de conteúdo das Competências Gerais da BNCC, nomeadamente da Competência Cultura Digital.

A análise do conteúdo é feita a partir dos procedimentos de análise do conteúdo propostos por Bardin (1977), com a criação de categorias a partir das leituras de Feenberg $(1999,2013,2017)$ e cujo procedimento será explicitado nas seções posteriores.

O objetivo é iniciar um diálogo em que a Competência Cultura Digital seja encaminhada em consonância com práticas pedagógicas críticas, admitindo para tanto que essa Competência da BNCC não seja construída exclusivamente em torno de artefatos e suas finalidades objetivas, mas que considere, ao mesmo tempo, os usos e apropriações desses artefatos nas sociedades e, mais especificamente, no âmbito da Educação.

\section{Perspectiva metodológica}

Esta análise partiu de alguns questionamentos das pesquisadoras: quais sentidos foram dados às novas tecnologias digitais na criação de uma Competência denominada Cultura Digital na BNCC? Quais os interesses envolvidos na criação de um conjunto de conhecimentos e fazeres (competência) sobre tecnologias digitais, a ser desenvolvido em todos os sistemas educacionais brasileiros? Que interesses podem ser produzidos ou reproduzidos a partir da implementação dos Objetivos de Aprendizagem dessa Competência em uma sala de aula?

Situado no domínio da pesquisa documental, o presente trabalho examina o texto da Competência Cultura Digital da BNCC. A análise do conteúdo, como forma de investigação do objeto, foi a metodologia selecionada por entender que a compreensão e a contextualização crítica do documento devem afastar-se ao máximo da interpretação espontânea, fundamentada em uma leitura superficial, que gera a "ilusão da transparência" dos fatos sociais (BARDIN, 1977, p. 28).

Para efeito desta análise, considerou-se que o contexto organizacional de produção dos currículos é, em si mesmo, um campo de interesses políticos e de disputa de poder relevante para a sua significação (SAVIANI, 2012a), o que pode ser constatado por meio de alguns documentos abordados neste trabalho (BRASIL, 1995, 2017b). Além disso, é preciso considerar que a construção de um currículo, ou neste caso, uma base curricular, também está influenciada em razão do período histórico, político e econômico em que se dá sua construção (BARDIN, 1977). 
A Competência Cultura Digital, assim como as demais Competências Gerais, foi dividida em grupos denominados Dimensões que, neste caso, são: Computação e Programação, Pensamento Computacional, e Cultura e Mundo Digital. Cada uma dessas Dimensões está dividida em Subdimensões, as quais abrangem objetivos para cada grupo de três anos do Ensino Fundamental ou Ensino Médio (BRASIL, 2017a).

Nesse contexto, foi selecionada uma das três Dimensões, o Pensamento Computacional e, dentro desta, a subdimensão intitulada Domínio de Algoritmos e seus objetivos específicos, como objetos para a análise crítica no âmbito deste trabalho. Seguindo a regra da representatividade de Bardin (1977), entende-se que todos os demais objetivos da competência Cultura Digital podem ser interpretados de forma semelhante, por serem parte do mesmo documento.

A seleção da subdimensão Domínio de Algoritmos para a análise apresentada no artigo está apoiada também no desenvolvimento de um projeto de pesquisa em fase de elaboração, no qual será dada ênfase à Dimensão Pensamento Computacional, em um trabalho com estudantes do Ensino Fundamental. Além disso, a escolha dessa Dimensão para a análise de conteúdo se deu pela maior número e melhor detalhamento dos Objetivos de Aprendizagem em Domínio de Algoritmos, permitindo assim uma exploração do material com maior riqueza para o estabelecimento tanto das unidades de análise, quanto das categorias.

Dessa forma, a escolha para este artigo privilegiou uma análise em profundidade, com maior detalhamento em uma Dimensão, em detrimento de uma análise em amplitude, porém, menos minuciosa.

Como unidade de análise, segundo Bardin (1977), foi utilizada a unidade de registro em nível semântico ilustrada pela autora como referente ou objeto. Neste caso, o texto é recortado em função de um eixo temático, agrupando à volta desse eixo tudo o que o texto exprime a seu respeito.

Esta análise é produzida a partir da teoria crítica da tecnologia de Feenberg $(1999,2013,2017)$, entendendo-se que essa teoria pode proporcionar um caminho para um diálogo crítico com as tecnologias digitais apresentadas no texto oficial da BNCC (BRASIL, 2017a). O posicionamento de Feenberg (1999) se baseia, principalmente, na interpretação de que as tecnologias admitem múltiplas influências e ramificações e que não se desenvolvem de forma única e linear ao longo da história das sociedades. Assim, o autor compreende que as tecnologias não são determinantes do desenvolvimento da sociedade, mas são parte dos múltiplos elementos que influenciam e são influenciados pelas pessoas.

As duas premissas sustentadas por Feenberg (1999) no campo da filosofia da tecnologia compõem a essência do que se denomina, neste artigo, de Teoria Crítica da Tecnologia, baseada no não determinismo e no desenvolvimento não linear das tecnologias. Essas premissas servem como suporte para a etapa de pré-análise dos dados (BARDIN, 1977) e a criação das categorias de análise que serão utilizadas neste artigo.

Entende-se que, no campo da Educação, essa visão se articula com as ideias de teóricos com perspectivas críticas, sendo selecionadas, em razão disso, para a composição desta análise, as concepções presentes na Pedagogia de Paulo Freire (FREIRE, 1994, 2002) e de Dermeval Saviani (SAVIANI, 2012a, 2012b). Pondera-se que as teorias desses pesquisadores apresentam possibilidades de compreensão e construção 
de currículos e de práticas pedagógicas que se vinculam à Competência Cultura Digital de forma mais crítica e libertadora, e menos 'coisificante' dos sujeitos da educação.

\section{O que significa compreender a cultura digital como uma competência na BNCC de forma crítica?}

Para Kuenzer (2002), o modelo de competência adotado nos documentos oficiais brasileiros atende mais aos interesses de um estado neoliberal do que às demandas reais da sociedade brasileira, pois são entendidas como o deslocamento de "[...] habilidades psicofísicas para o desenvolvimento de competências cognitivas complexas, mas sempre para atender às exigências do processo de valorização do capital" (KUENZER, 2002, p. 3).

As competências, no entanto, constituem aspecto fundamental para a construção dos objetivos de aprendizagem, e são de particular importância no contexto da BNCC (BRASIL, 2017a). Portanto, a compreensão e a contextualização das Competências Gerais se constituem em fatores essenciais para a compreensão de seu papel no contexto da legislação educacional brasileira e para o estabelecimento de um diálogo com as concepções críticas da tecnologia e da educação.

Evidencia-se ainda que a Base Nacional Comum Curricular tem caráter complementar aos currículos: a BNCC determina as aprendizagens essenciais em cada etapa e os currículos, organizados pelas mantenedoras de cada sistema público ou privado, fazem a adaptação desses conteúdos à realidade local (BRASIL, 2017a). Tais adaptações devem ser realizadas considerando a autonomia de cada rede de ensino ou instituição escolar, além do contexto social e das características dos estudantes, em conformidade com o disposto pelo Conselho Nacional de Educação (BRASIL, 2017b).

Embora toda legislação seja balizadora de ações, ou seja, determina certos limites, é necessário que não se mostrem "burocratizadoras da mente", como pondera Freire (2002, p. 43). Em outras palavras, é preciso que essa legislação não force a ação pedagógica na direção de uma realidade pronta e acabada, de uma inevitabilidade. Por isso, as competências deveriam ser parte de uma Educação que considera a necessidade atual como transitória e inacabada e, por isso mesmo, não se limitando a puro treino, para não contribuir para o processo da burocratização mental (FREIRE, 2002) que, ao mesmo tempo, coloca os educandos face a uma situação intransponível, dada por outros e que não Ihes cabe modificar (FREIRE, 1994).

Destaca-se que as competências são um dos dois fundamentos pedagógicos da BNCC (BRASIL, 2017a). Dessa maneira, é importante considerar, também, que na prática pedagógica contemporânea, existe a possibilidade de não haver uma relação necessariamente dicotômica entre competência e conteúdo. Se por um lado Perrenoud (1999) assevera que a abordagem por competências não rejeita nem os conteúdos, nem as disciplinas, também é preciso observar que, muitas vezes, o ensino dos conteúdos é priorizado em detrimento ao estímulo à criticidade e à curiosidade, dando ao conhecimento, assim como à sociedade e à realidade que esses conteúdos representam, o verniz de uma verdade pronta e acabada (FREIRE, 2002, p. 24).

Isso posto, no que tange à divisão entre competência e conteúdo, podese assumir o olhar de Freire (2002), que explica que não cabe separar o ensino dos conteúdos da formação ética dos educandos, sendo as divisões mecanicistas um entrave à prática crítica e reflexiva do professor e da professora. 
A Competência Cultura Digital na BNCC visa ensinar a "[...] utilizar e criar tecnologias digitais de informação e comunicação de forma crítica, significativa, reflexiva e ética nas diversas práticas sociais" (BRASIL, 2017a, p. 9).

Antes de se discutir sobre a viabilidade técnica e de infraestrutura para a concretização desse objetivo maior, no entanto, é preciso abordar a questão determinante com relação à Competência em si mesma, e quais pautas sociais ela verdadeiramente atende ao ser inserida como aspecto central no sistema de escolarização formal.

$\mathrm{Na}$ BNCC, a Competência Cultura Digital apresenta-se em três grupos, denominados, no documento, como dimensões: Computação e Programação, Pensamento Computacional, e, Cultura e Mundo Digital. Cada uma dessas Dimensões está dividida em Subdimensões. No quadro 1 está representada a organização da Cultura Digital na BNCC, juntamente com o objetivo geral de cada subdimensão (BRASIL, 2017a).

Quadro 1 - Dimensões e Subdimensões da Competência Cultura Digital na BNCC

\begin{tabular}{|c|c|c|}
\hline Dimensões & Subdimensão & Descrição da subdimensão \\
\hline \multirow{3}{*}{$\begin{array}{l}\text { Computação e } \\
\text { Programação }\end{array}$} & $\begin{array}{l}\text { Utilização de ferramen- } \\
\text { tas digitais }\end{array}$ & Utilização de ferramentas digitais para aprender e produzir. \\
\hline & Produção multimídia & $\begin{array}{l}\text { Utilização de recursos tecnológicos para desenhar, desenvolver, publicar, } \\
\text { testar e apresentar produtos para demonstrar conhecimento e resolver } \\
\text { problemas. }\end{array}$ \\
\hline & $\begin{array}{l}\text { Linguagens de Progra- } \\
\text { mação }\end{array}$ & Utilização de linguagens de programação para solucionar problemas. \\
\hline \multirow[t]{2}{*}{$\begin{array}{l}\text { Pensamento } \\
\text { Computacional }\end{array}$} & Domínio de algoritmos & $\begin{array}{l}\text { Compreensão e escrita de algoritmos. Avaliação de vantagens e desvantagens } \\
\text { de diferentes algoritmos. Utilização de classes, métodos, funções e parâmetros } \\
\text { para dividir e resolver problemas. }\end{array}$ \\
\hline & $\begin{array}{l}\text { Visualização e análise } \\
\text { de dados }\end{array}$ & $\begin{array}{l}\text { Utilização de diferentes representações e abordagens para visualizar e } \\
\text { analisar dados. }\end{array}$ \\
\hline \multirow{2}{*}{$\begin{array}{l}\text { Cultura e } \\
\text { Mundo Digital }\end{array}$} & Mundo digital & $\begin{array}{l}\text { Compreensão do impacto das tecnologias na vida das pessoas e na sociedade, } \\
\text { incluindo nas relações sociais, culturais e comerciais. }\end{array}$ \\
\hline & Uso ético & $\begin{array}{l}\text { Utilização das tecnologias, mídias e dispositivos de comunicação modernos } \\
\text { de forma ética, comparando comportamentos adequados e inadequados. }\end{array}$ \\
\hline
\end{tabular}

Fonte: Brasil (2017a).

São elencadas, ao todo, sete Subdimensões e cada uma delas, por sua vez, pode ter uma ou mais divisões, aqui denominadas Categorias. Cada Categoria tem objetivos específicos a serem atingidos em certas etapas do Ensino Fundamental e do Ensino Médio. Esses marcos definidos pelo documento são os Objetivos de Aprendizagem.

Cada categoria possui quatro Objetivos de Aprendizagem, definidos de forma padronizada para todas as Categorias, em todas as Subdimensões: até o $3^{\circ}$ ano do Ensino Fundamental; até o $6^{\circ}$ ano do Ensino Fundamental; até o $9^{\circ}$ ano do Ensino Fundamental; e, até o $3^{\circ}$ ano do Ensino Médio.

Segue, no quadro 2, o texto extraído do documento original (BRASIL, 2017a) com os Objetivos de Aprendizagem para cada etapa dos Ensinos Fundamental e Médio que, em conjunto, devem contribuir para a aquisição do objetivo previsto para a Dimensão Pensamento Computacional (quadro 1). 
Quadro 2 - Objetivos de Aprendizagem (OA) da Subdimensão Domínio de Algoritmos

\begin{tabular}{|c|c|c|c|c|}
\hline \multirow{2}{*}{$\begin{array}{c}\text { Categorias da } \\
\text { Subdimensão Domínio } \\
\text { de Algoritmos }\end{array}$} & \multicolumn{4}{|c|}{ Objetivos de Aprendizagem } \\
\hline & $\begin{array}{c}\text { Até o } 3^{\circ} \text { ano do Ensino } \\
\text { Fundamental }\end{array}$ & $\begin{array}{c}\text { Até } 06^{\circ} \text { ano do Ensino } \\
\text { Fundamental }\end{array}$ & $\begin{array}{c}\text { Até o } 9^{\circ} \text { ano do Ensino } \\
\text { Fundamental }\end{array}$ & $\begin{array}{c}\text { Até o } 3^{\circ} \text { ano do Ensino } \\
\text { Médio }\end{array}$ \\
\hline $\begin{array}{l}\text { Compreensão e escrita de } \\
\text { algoritmos }\end{array}$ & $\begin{array}{l}\text { Utiliza recursos tecno- } \\
\text { lógicos (por exemplo, } \\
\text { enigmas e programas de } \\
\text { raciocínio lógico) para } \\
\text { solucionar problemas } \\
\text { adequados à sua idade. }\end{array}$ & $\begin{array}{l}\text { Desenvolve compreensão } \\
\text { simples de um algoritmo } \\
\text { (por exemplo, pesquisa, } \\
\text { sequência de eventos, } \\
\text { organização), utilizando } \\
\text { exercícios sem compu- } \\
\text { tador. }\end{array}$ & $\begin{array}{l}\text { Escreve um algoritmo } \\
\text { como uma sequência de } \\
\text { instruções que podem } \\
\text { ser processadas por um } \\
\text { computador. }\end{array}$ & $\begin{array}{l}\text { Explica como sequência, } \\
\text { seleção, iteração e recur- } \\
\text { são são blocos que com- } \\
\text { põem os algoritmos. }\end{array}$ \\
\hline $\begin{array}{l}\text { Avaliação de vantagens } \\
\text { e desvantagens de dife- } \\
\text { rentes algoritmos }\end{array}$ & --- & --- & $\begin{array}{l}\text { Descreve vantagens e } \\
\text { desvantagens associadas } \\
\text { a diferentes algoritmos } \\
\text { utilizados para solucionar } \\
\text { o mesmo problema. }\end{array}$ & $\begin{array}{l}\text { Avalia as vantagens e des- } \\
\text { vantagens de diferentes } \\
\text { algoritmos utilizados para } \\
\text { solucionar o mesmo pro- } \\
\text { blema. }\end{array}$ \\
\hline $\begin{array}{l}\text { Utilização de classes, mé- } \\
\text { todos, funções e parâme- } \\
\text { tros para dividir e resolver } \\
\text { problemas }\end{array}$ & --- & $\begin{array}{l}\text { Compreende e utiliza os } \\
\text { passos básicos da solu- } \\
\text { ção de problemas por } \\
\text { algoritmos (por exem- } \\
\text { plo, questão-problema e } \\
\text { exploração, avaliação de } \\
\text { amostras de instâncias, } \\
\text { design, implementação } \\
\text { e testes). }\end{array}$ & $\begin{array}{l}\text { Utiliza os passos básicos } \\
\text { da solução de problemas } \\
\text { por algoritmo para resol- } \\
\text { ver questões. }\end{array}$ & $\begin{array}{l}\text { Utiliza classes e métodos, } \\
\text { funções e parâmetros } \\
\text { pré-definidos para dividir } \\
\text { um problema complexo } \\
\text { em partes mais simples } \\
\text { e resolvê-lo. }\end{array}$ \\
\hline
\end{tabular}

Fonte: Brasil (2017a).

A subdimensão selecionada para análise, Domínio de Algoritmos, é a que apresenta maior número de Objetivos de Aprendizagem para o Ensino Fundamental. Conforme referido anteriormente, a análise de conteúdo de uma das subdimensões e seus objetivos serão tomadas como representativas da íntegra do documento, seguindo a regra da representatividade (BARDIN, 1977).

A leitura espontânea do documento levou a questionamentos que produziram a necessidade desta análise, sendo os principais: quais valores estiveram impregnados no projeto da BNCC e que, particularmente com relação às novas tecnologias digitais, culminaram na necessidade de criação de uma competência denominada Cultura Digital? A criação de um conjunto de conhecimentos e fazeres, denominado na BNCC como Competência, a ser desenvolvida de forma ampla, generalista (para não dizer superficial) em todos os sistemas educacionais brasileiros é interessante? Que diálogos podem ser produzidos a partir desta Competência?

A partir daí, entendeu-se que as relações sociais são essenciais para explicar a hegemonia tecnológica, sendo necessário analisar do ponto de vista dos diversos atores dessas redes complexas (FEENBERG, 2013). A hegemonia a que o autor se refere corresponde a um aspecto tão arraigado na sociedade que, para os dominados, parece algo natural e imutável.

Feenberg (2013) entende, ainda, que esta hegemonia possui dois aspectos hermenêuticos, chamados de significado social e horizonte cultural. O significado social se refere às apropriações que os diversos atores fazem dos artefatos, modificando seu desenho e suas funções sociais. O significado social, assim, promove um alinhamento entre as metas criadas pelos grupos que concebem esses artefatos, muitas vezes alienadas e alienantes, e os significados produzidos e reproduzidos socialmente nos diferentes contextos de uso desses artefatos. 
O outro aspecto da hegemonia tecnológica dado por Feenberg (2013) é o horizonte cultural, que faz menção a um cenário de suposições e certezas socialmente difundidas e aparentemente inquestionáveis nas quais as técnicas e os artefatos se fundamentam.

Desprovida de significado social, a tecnologia é essencial, tem uma meta clara a ser cumprida, sendo determinante para a sociedade, ao invés de ser determinada por fatores sociais e técnicos (FEENBERG, 2013). Sem significado social, é gerada uma assimetria e um processo de hierarquização, onde o enfoque está deslocado do ser humano e de sua integralidade para a técnica e o artefato, desdobrando-se em uma ordem tecnocrática, a qual Feenberg (2013) atribui o nome de Determinismo Tecnológico.

Com base nos conceitos acima expostos, durante as etapas de pré-análise e de exploração do material, foram estabelecidas 5 categorias que nortearam esta análise, indicadas no quadro 3.

Quadro 3 - Categorias de análise com base da Teoria Crítica da Tecnologia

\begin{tabular}{|c|c|}
\hline Categoria & Descrição \\
\hline $\begin{array}{l}\text { Determinação } \\
\text { pelo artefato }\end{array}$ & $\begin{array}{l}\text { Primazia dos artefatos sobre as pessoas. O processo de determinação é dado quando se identifica } \\
\text { no artefato ou no discurso subjacente a ele, elementos que reificam a tecnologia. A tecnologia } \\
\text { é considerada ponto determinante em todos os aspectos da vida humana: é ela quem molda e } \\
\text { direciona a sociedade (FEENBERG, 2013). }\end{array}$ \\
\hline Linearidade & $\begin{array}{l}\text { Primazia do progresso científico sobre os valores humanos. É identificado pela presença de um } \\
\text { senso de progresso unilinear das tecnologias. Essa direção fixa ocorre sempre das configurações } \\
\text { mais simples para as mais complexas, eficazes, por meio de uma sucessão definida de fatos que } \\
\text { concorrem para este fim (FEENBERG, 2013). }\end{array}$ \\
\hline Instrumentalismo & $\begin{array}{l}\text { Pressupõe um processo de desenvolvimento de artefatos desprovido de valores e direcionado unicamente } \\
\text { para a eficiência. A tecnologia é vista como um instrumento funcional que atende às necessidades } \\
\text { das pessoas por sua eficiência nas tarefas (FEENBERG, 2013). Nessa visão, não se considera que o } \\
\text { artefato possa ter incorporado em sua estrutura e/ou funcionamento os reflexos dos valores das } \\
\text { pessoas que o desenvolveram. A finalidade do artefato é dada pelo seu uso e não está contida nele. }\end{array}$ \\
\hline Neutralidade & $\begin{array}{l}\text { Pressupõe que as pessoas, ao adotarem um artefato, o fazem de forma isenta e orientadas somente } \\
\text { para a eficiência. Decorrendo da visão Instrumentalista, o valor atribuído à tecnologia se refere } \\
\text { exclusivamente a sua eficiência perante a resolução de um problema ou um conjunto de problemas. } \\
\text { Sendo a Tecnologia uma ferramenta eficiente, as escolhas técnicas são feitas unicamente com vistas } \\
\text { a esta eficiência, que pode ser usada para ajudar a criar diferentes estilos de vida. }\end{array}$ \\
\hline $\begin{array}{l}\text { Visão crítica da } \\
\text { tecnologia }\end{array}$ & $\begin{array}{l}\text { Os contextos sociais de uso e de criação dos artefatos são considerados de forma prioritária na } \\
\text { apropriação das tecnologias. O mundo social não é apenas o local onde se acham as tecnologias, } \\
\text { mas um elemento que as atravessa e impregna de significados (FEENBERG, 1999). A eficiência é } \\
\text { apenas mais um critério de seleção, dentre outros presentes no contexto. }\end{array}$ \\
\hline
\end{tabular}

Fonte: Feenberg $(2013,2017)$.

Conforme Feenberg (2013), o Determinismo se refere a um processo no qual a sociedade é expropriada de oportunidades de participação, criação, direcionamento, usos e aproveitamento dos artefatos: a vida cotidiana, o trabalho, a educação, a saúde, existem e são ditados pelas tecnologias e seus artefatos contemporâneos. A tecnologia pertence, por assim dizer, aos técnicos: às pessoas comuns, cabe o dever de fazer uso dos artefatos 'corretamente', da forma como foram desenhados.

De forma oposta, para a Filosofia Crítica da Tecnologia (FEENBERG, 1999), a percepção da tecnologia como ferramenta desprovida de valores em sua forma e função não se sustenta, pois assume que existe um aspecto técnico, mas que a função social dos artefatos modifica e é modificada simultaneamente ao longo dos usos 
e apropriações. Interpretada a partir da Filosofia Crítica da Tecnologia proposta por Feenberg (2013), a tecnologia incorpora valores sociais específicos que não podem ser representados por paradigmas abstratos como 'eficiência', por exemplo, embora a eficiência de um artefato em dada situação contribua para sua adoção. Dessa forma, a categoria Visão Crítica da Tecnologia emerge como comparativo necessário para a diferenciação das demais categorias.

A partir das características do Determinismo dadas por Feenberg (2013) foi criada a categoria Determinação pelo artefato. Tanto no caráter do texto, quanto na própria organização textual, foi evidenciada a construção de uma Competência que visa o desenvolvimento de saberes e fazeres característicos dos meios digitais. Em virtude disso, se entende que a Cultura Digital como competência na BNCC se mostra assente no Determinismo Tecnológico (FEENBERG, 2013), uma vez que propõe uma espécie de inclusão ou letramento digital, o qual tem a finalidade ensinar não apenas conhecimentos, mas principalmente práticas (saber fazer) relativas ao contexto digital.

Nesta continuidade, analisa-se que a própria elaboração de um conjunto de habilidades e conhecimentos denominado Cultura Digital denota o imperativo tecnológico característico do Determinismo e sustenta a categoria de Determinação pelo artefato. Essa categoria assume que a tecnologia se desenvolve de maneira autônoma e independente, ditando o compasso da vida em sociedade; e a Educação cumpre o papel de ensinar às pessoas como acompanhar essa Cultura Digital, da qual a maioria das pessoas parece estar à margem de qualquer interferência.

$\mathrm{O}$ conceito de Linearidade em Ciência admite que, se um artefato ou técnica surge em um momento mais recente da história, ele necessariamente é melhor/mais eficaz/mais complexo que seus antecessores (FEENBERG, 2013). Esse tipo de conclusão desconsidera que, frequentemente, há mais do que uma solução viável para um problema e que essas soluções podem se desenvolver paralelamente, ou em uma sucessão de fatos diferente em relação ao plano inicial, não necessariamente seguindo uma lógica temporal - do mais antigo ao mais recente.

Com base nesse conceito, a categoria de análise Linearidade (FEENBERG, 1999) emergiu para a composição desta análise. Durante a leitura e exploração do material, foram percebidos indicativos de uma visão linear do progresso das Ciências, que se revelou na construção dos Objetivos de Aprendizagem dentro da Competência Cultura Digital.

No texto da Competência Cultura Digital, de maneira geral, a categoria Linearidade pode ser observada na estruturação de um percurso linear de aquisição de habilidades e conhecimentos de forma lógica ao longo do tempo escolar, evidenciados no quadro 2. Especificamente na subdimensão Domínio de Algoritmos, a categoria Linearidade se mostra no estabelecimento de uma sequência de atividades que, mesmo não utilizando o computador, devem confluir para tanto. Na categoria Compreensão e Escrita de Algoritmos, no quadro 2, é possível perceber essa sequência, observando que, até o final do $6^{\circ}$ ano do Ensino Fundamental, solicita-se que o estudante compreenda e escreva um algoritmo simples utilizando exercícios sem computador, mas até o final do $9^{\circ}$ ano da mesma etapa do ensino, o estudante já deve ser capaz de escrever um algoritmo que pode ser processado por um computador. Assim sendo, admite-se que, mesmo sem o uso do artefato, o objetivo da aprendizagem é voltado para ele. 
A leitura do material evidenciou, ainda, nos Objetivos de Aprendizagem, que a Tecnologia tem um aspecto instrumental, ou ainda funcional, muito pronunciado, a partir do que foi criada a categoria Instrumentalismo. Dentro da Teoria Crítica da Tecnologia, Feenberg (2013) compara a perspectiva instrumental à moldura de obras de arte expostas em museus: assim como as molduras, é claro que as tecnologias são úteis, mas não é por esse motivo que estão disponíveis para a sociedade. Acreditar que todas as tecnologias são criadas e disponibilizadas unicamente porque são eficientes em alguma tarefa, é adotar um ponto de vista que as considera, primariamente, por sua função técnica, e desprezar que os artefatos são criados por pessoas, em condições sociais e períodos históricos circunscritos que influenciam suas decisões e ações.

Para Feenberg (1999, p. 212), esta maneira "instrumentalista" de pensar os artefatos assume que a tecnologia é social apenas a partir de sua função técnica, e desconsidera os usos sociais. Dessa maneira, continua o autor, uma tecnologia somente é social quando está sendo aplicada, mas, fora de um contexto de uso, poderia ser resumida a seus aspectos técnicos, sendo esses aspectos considerados resíduos não sociais.

Na etapa de exploração do material, se sobressaiu também o aspecto neutro da Tecnologia, algo que frequentemente é decorrente da visão instrumentalista abordada previamente. Essa neutralidade é um horizonte que só pode ser alcançado se se pensar que a Tecnologia é instrumento eficiente para o progresso humano. Sendo eficiente e objetivando o progresso, não cabem controvérsias políticas ou justificativas filosóficas para as escolhas técnicas realizadas (FEENBERG, 1999).

Conforme conceituado no quadro 3, a categoria Neutralidade evoca a eficiência como a única essência da Tecnologia e, sendo assim, nossas escolhas em relação a Tecnologia nos tornam reféns dessa eficiência. Logo, dentro de um paradigma de neutralidade, se uma tecnologia é considerada pelas pessoas que a utilizam (e não participaram de seu desenvolvimento) como ineficiente para certas tarefas, isso deve ser atribuído às formas de uso das tecnologias, e não ao artefato em si. A neutralidade obscurece o diálogo: se uma tecnologia existe, logo, ela é eficiente para a humanidade e, por isso, não cabe discutir a necessidade ou não de utilizá-la (FEENBERG, 2013).

Há, portanto, um verniz de neutralidade ao indicar o direcionamento correto da Educação Básica, com vistas à suposta melhoria da educação e das aprendizagens, quando se estabelece que as decisões pedagógicas precisam estar orientadas para o desenvolvimento de uma Competência Digital (BRASIL, 2017a), circunscrevendo de forma bastante precisa os objetivos para cada etapa, o que performa o Determinismo Tecnológico conforme o compreende Feenberg (2013). O Determinismo é pronunciado, especialmente quando o próprio documento expressa que, embora existam muitas regionalidades, há uma forma determinada de assegurar a aprendizagem com as tecnologias (BRASIL, 1996, 2017a).

Logo, considerando a função da BNCC, em relação à Educação Básica (BRASIL, 2017a), e considerando também que essa função está sustentada pela LDB (BRASIL, 1996), é possível constatar que as escolhas técnicas feitas ao longo do texto da Competência Cultura Digital deliberam sobre o modelo de educação e de educando que deve ser formado a partir dessa proposta curricular: que domine as ferramentas digitais propostas no escopo da Competência, em todas as áreas do conhecimento e que esteja, dessa forma, adequado ao paradigma social vigente. 
Este pensamento se alinha às considerações de Feenberg (2013), que assevera que as mediações tecnológicas moldam diversos aspectos da vida e implicam em diferentes escolhas; todas essas escolhas, porém, compõem um espectro previamente programado, contido nos valores subjacentes ao artefato. Por isso, nossas ações são, de certa maneira, limitadas em função de escolhas técnicas. Esses valores subjacentes aos artefatos utilizados visam a um ou mais objetivos, que serão comuns a todos os usuários deste instrumento - neste caso, uma base comum a todos os currículos brasileiros (BRASIL, 1996, 2017a).

\section{Intervenções democráticas, práticas pedagógicas e possibilidades críticas no contexto da cultura digital na BNCC}

Enquanto a Competência Cultura Digital na BNCC expõe uma visão predominantemente determinada por artefatos, linear, instrumental e neutra, que se desfia em uma Tecnologia focada em artefatos, que desvaloriza as diferentes perspectivas culturais, esmaece os valores estruturais nela presentes e, consequentemente, determina o direcionamento da sociedade, a Visão Crítica da Tecnologia propõe leituras e intervenções que podem ressignificar esse modelo (FEENBERG, 2013).

Feenberg (2013) ainda chama a atenção para o fato de que o socialmente desejável é, na verdade, uma visão hegemônica, e não uma visão universal, o que reforça a ideia de que os objetivos e artefatos selecionados para a composição da Competência Cultura Digital, enquanto prática articulada às práticas pedagógicas de todas as disciplinas, é fruto de uma escolha técnica codificada em objetivos factíveis para cada etapa da Educação Básica, desconsiderando-se toda a estrutura física necessária e frequentemente ausente. Partindo disso, não se pode considerar que a Competência Cultura Digital seja despojada de determinações ou escolhas, ou que ela seja auto-determinada, com base no critério da eficiência: ela reflete uma escolha apropriada a um direcionamento social determinado por grupos sociais que estiveram envolvidos em sua construção. Por isso, é preciso compreender o contexto de elaboração da BNCC e das Competências Gerais.

Entendida a partir do viés histórico-crítico, a Competência Cultura Digital na BNCC busca, desta maneira, manter uma essência gnosiológica descolada de seu papel social, o que também demonstra seu alinhamento com uma pedagogia tradicional. A pedagogia tradicional, segundo aponta Saviani (2012b), se baseia no fato de que os estudantes são seres abstratos, expressões particulares de uma essência única que caracteriza a existência humana, o que, embora não seja descrito expressamente, justifica uma padronização de conhecimentos e processos. Desta forma, tendo uma base pedagógica tradicional, a composição da Competência Cultura Digital resulta em uma visão unidirecional das apropriações tecnológicas.

Saviani (2012b) ressalta que as necessidades imediatas de aprendizagem dos sujeitos são relativas à situação em que se encontram, e não às que escolheu. Desse modo, o autor indica que a autonomia, a criatividade e a originalidade desses sujeitos, condições exortadas e objetivos das Competências da BNCC, existem, mas limitadas pelas relações sociais em que se situam. Dessa maneira, a ideia de que o estudante está livre para participar, criar e se apropriar dos conhecimentos, em especial da 
Competência Cultura Digital, a partir de sua inserção no contexto pedagógico, fica comprometida.

Ao buscar compreender essa participação no processo de apropriação e criação pelo olhar da Teoria Crítica da Tecnologia, temos em Feenberg (2017) que esse processo não necessariamente se dá na forma do desenvolvimento de um artefato novo, como um robô ou a criação de um código. Ao mesmo tempo, o autor chama a atenção para o fato de que a participação dos grupos sociais pode constituir uma antítese aos programas elaborados pelas forças sociais hegemônicas. Feenberg (2017) denomina essa antítese de anti-programas, que, simplificadamente, podem ser explicados como apropriações características desses artefatos ou sistemas técnicos por certos grupos sociais, ressignificando-os de acordo com seus interesses. Feenberg (1999) destaca que a tecnologia passa por transformações sociais, por ele chamadas de intervenções democráticas, as quais integram um fenômeno maior, chamado Racionalização Democrática, que, por sua vez, é uma forma de intervenção na qual estruturas não democráticas, enraizadas nas tecnologias modernas, são desafiadas por meio de diferentes ações.

As intervenções democráticas, no caso da BNCC, teriam o papel de alterar a estrutura verticalizada de imposição de uma ordem técnica para a Educação. Essas intervenções, que provocam e deslocam o papel das tecnologias na sociedade, podem ocorrer sob três formatos (FEENBERG, 1999): controvérsias técnicas (expressas na forma de manifestações, protestos, boicotes, petições online, etc); apropriações criativas (por exemplo, utilização de artefatos para finalidades para as quais não foram inicialmente desenhados, ou hacking); ou ainda, por meio de diálogos participativos entre leigos e especialistas.

No caso da BNCC, as intervenções democráticas se deram, ao longo da sua construção, em pontos bastante específicos, coordenados pelas instituições elaboradoras do documento, restando pouco espaço para a participação dos grupos interessados. Em ordem cronológica, na construção da BNCC houve um seminário do qual participaram as pessoas (professores e professoras especialistas e da Educação Básica) que viriam a compor a comissão de elaboração do documento; posteriormente, de setembro a dezembro de 2016, aconteceu uma consulta pública, baseada na internet, por meio da qual a comissão de elaboração registrou aproximadamente 12 milhões de contribuições, analisadas e incorporadas à segunda versão, a qual foi encaminhada para o Conselho Nacional de Educação (CNE). O CNE conduziu, então, de junho a agosto de 2016, em parceria com os estados, a realização de 27 seminários estaduais, para discussões e contribuições à segunda versão; nessa etapa presencial, porém, houve a participação de apenas cerca de 9.000 pessoas, representando os profissionais da educação e estudantes. Dos seminários estaduais se iniciou a elaboração da terceira versão, com o qual contribuíram especialistas brasileiros e estrangeiros convidados pelo CNE e pela Comissão de Elaboração da BNCC, processo este que finda em abril de 2017 com a entrega da terceira versão do documento ao CNE. Em dezembro do mesmo ano, a versão final da BNCC para a Educação Infantil e para o Ensino Fundamental foi homologada (BRASIL, 2020).

Feenberg (1999) também lembra que a relação da tecnologia com a sociedade não se dá apenas em termos de apropriações e usos dos objetos técnicos. A participação social deve existir desde a concepção técnica, visto que os artefatos incorporam os 
interesses de seus desenvolvedores e direcionam o comportamento e as decisões que os sujeitos precisam tomar ao fazer uso desses artefatos, tendo, portanto, um caráter autoritário em relação aos usuários. Com isso, o autor defende um processo de desenvolvimento socialmente consciente das tecnologias.

Interpretadas desta forma, é possível afirmar que as escolhas técnicas, feitas no âmbito do texto da Competência Cultura Digital como um todo, podem não representar adequadamente as diversidades sociais envolvidas no processo de apropriação das tecnologias no ambiente da escola.

Pode-se compreender, ainda, a partir das categorias de análise (quadro 3) e do princípio da representatividade de Bardin (1977), que o Determinismo Tecnológico está presente no texto analisado. Da mesma forma, é possível notar que há uma verdade técnica a ser transmitida para o estudante - no caso do texto analisado, o domínio de uma forma de expressão denominada algoritmo -, sob a premissa de que esta, assim como todas as demais no escopo da Competência Cultura Digital, fortalece as aprendizagens essenciais definidas pela própria BNCC. As diferenças sociais e regionais, bem como a maior ou menor abertura para discussão desses parâmetros, são todas deixadas a cargo dos currículos e de suas gestões locais (BRASIL, 2017a).

A partir dessas interpretações, pondera-se o processo de Racionalização Democrática (FEENBERG, 1999), no âmbito da BNCC, como base para a composição de currículos e de práticas pedagógicas críticas. Entende-se que um caminho possível para essa integração se assenta em um diálogo entre o conceito de Racionalização Democrática de Feenberg (1999) e a pedagogia histórico-crítica de Saviani (2012a). Neste caso, a visão de proporcionar a todos os estudantes aprendizagens e vivências relacionadas com as novas tecnologias, por meio da regulamentação de uma Base Nacional, pode ser entendida como um importante marco educacional, porque reconhece a importância das práticas circunscritas no espaço escolar e considera que este espaço é um importante local de construção e de disputa (SAVIANI, 2012a), favorecendo as discussões, apropriações e intervenções democráticas.

Dessa forma, a Racionalização Democrática (FEENBERG, 1999), no contexto da Cultura Digital como Competência na BNCC, deve ocorrer posteriormente à construção do conceito oficial expresso no documento, nomeadamente na prática de cada docente e no contexto de cada unidade escolar.

Saviani (2012a) entende que o ensino deve ser constituído de uma base instrumental, sem a qual os diálogos e discussões não podem se sustentar. Nesse sentido, as tecnologias digitais podem ser consideradas parte de uma base técnica e instrumental curricular e devem estar presentes nas práticas pedagógicas (SAVIANI, 2012a). Porém, para o a utor, a instrumentalização deve acontecer como consequência da problematização da prática social, "[...] atingindo o momento catártico que concorrerá na especificidade da matemática, da literatura, etc... para alterar qualitativamente a prática de seus alunos como agentes sociais" (SAVIANI, 2012a, p. 80). À vista disso, Saviani (2012a) imprime na figura docente o papel de condutor desse processo, de forma política e ideologicamente situada, o que leva cada professor e professora a contribuir, dentro de sua especificidade, para a transformação estrutural da sociedade.

Entende-se aqui que o processo defendido por Saviani (2012a) se aproxima do conceito de Racionalização Democrática proposto por Feenberg (1999), considerando que os múltiplos atores envolvidos na ação pedagógica irão realizar, dentro de seu 
escopo de atuação social, as apropriações condizentes com a sua situação em relação às tecnologias propostas.

Nesses casos, segundo Feenberg (1999), as apropriações podem seguir dois caminhos: serem suprimidas, seja por investimentos de partes interessadas na permanência do código técnico, seja por uma supressão eficaz das resistências locais, por forças hierárquicas ou burocráticas; ou, numa perspectiva um pouco mais otimista, essas apropriações podem ser internalizadas pelo código técnico, resultando em uma aprendizagem com a comunidade local e uma inovação baseada nesses diálogos.

Considerando essas apropriações à luz da educação como prática de liberdade, pontuada por Freire (1994), as práticas docentes devem estimar que os sujeitos não se limitem a buscar encaixe na sociedade: pelo contrário, essas práticas devem fornecer as bases para uma atitude crítica que leve à superação e à transformação dessa mesma sociedade, dedicando-se, em última instância, a garantir a formação de um educandosujeito e não de um educando-objeto (FREIRE, 1994, 2002).

Freire (2002, p. 13) destaca, em Pedagogia da autonomia, que "[...] inexiste validade no ensino de que não resulta um aprendizado em que o aprendiz não se tornou capaz de recriar ou de refazer o ensinado", assumindo, dessa forma, que a lógica do ensino deve necessariamente ser transformadora, e não um mero treinamento para responder à necessidades imediatas.

Quanto à condução pedagógica desse processo e às apropriações dos/as docentes para o processo de ensino, é necessário lembrar também que os diferentes pensamentos pedagógicos evidenciam as disputas no campo da Educação (SAVIANI, 2012a). Portanto, pedagogias tradicionais, que se focam somente no caráter instrumental e disciplinar, seriam sistemas desenvolvidos para não criticizar ou propor diálogos entre os instrumentos técnicos e os sistemas sociais onde estão inseridos, sendo, assim, hermeticamente construídas para a perpetuação das culturas hegemônicas e não favorecendo apropriações críticas das tecnologias.

É possível perceber esse aspecto fechado e pouco reflexivo na Competência Cultura Digital (BRASIL, 2017a) ao olhar para a forma de organização das suas dimensões e subdimensões, evidenciando seu foco Instrumental, destacado na categoria de análise Instrumentalista.

Na perspectiva crítica adotada neste trabalho, contudo, o foco instrumental da Cultura Digital na BNCC deve ser interpretado para além de sua dimensão técnica. No âmbito da pedagogia crítica, Saviani (2012b) afirma que todo o processo da Educação está impregnado de sentido e assume que o conhecimento nunca é neutro: o ato de educar possui um caráter gnosiológico, ou seja, um sentido empírico, relativo ao conhecimento da realidade, ao mesmo tempo em que possui um aspecto ideológico, o que significa que também está associado com interesses e necessidades das pessoas. Para o autor, os interesses impulsionam o conhecimento, mas, ao mesmo tempo, Ihe impõem certos limites relativos à orientação desses interesses, sendo este o ponto de conflito da Educação.

Quanto à tecnologia digital em si mesma, no sentido dos artefatos presentes nos textos da BNCC, observa-se um direcionamento para certos tipos de aprendizagens que não estão diretamente relacionadas com os Objetivos de Aprendizagem (OA) presentes nas disciplinas no mesmo documento e que são estritamente técnicos, como escrever "[...] um algoritmo como uma sequência de instruções que podem ser 
processadas por um computador" (BRASIL, 2017a), um evidente caráter Instrumental e Neutro (quadro 2). Segundo a interpretação da Teoria Crítica da Tecnologia, a escolha desses artefatos não estaria assentada na simples eficiência destes no ensino ou na aprendizagem dos estudantes, mas sim responde aos vários interesses e ideologias selecionados, entre os muitos disponíveis, para a construção da Competência Cultura Digital. Isso não quer dizer, necessariamente, que estes são conhecimentos desnecessários, tampouco reduz a sua eficiência, mas direciona os resultados de acordo com um programa social que está além da Educação em si mesma (FEENBERG, 2013).

Finalizando, é apresentada no quadro 4 a sumarização das características do Determinismo Tecnológico encontradas nas Categorias da Subdimensão Domínio de Algoritmos.

Quadro 4 - Características deterministas identificadas nas categorias da subdimensão Domínio de Algoritmos, na Competência Cultura Digital da BNCC

\begin{tabular}{|c|c|c|c|}
\hline & $\begin{array}{c}\text { Compreensão e escrita de } \\
\text { algoritmos }\end{array}$ & $\begin{array}{l}\text { Avaliação de vantagens e } \\
\text { desvantagens de diferentes } \\
\text { algoritmos }\end{array}$ & $\begin{array}{l}\text { Utilização de classes, métodos, } \\
\text { funções e parâmetros para dividir } \\
\text { e resolver problemas }\end{array}$ \\
\hline $\begin{array}{l}\text { Determinação pelo } \\
\text { artefato }\end{array}$ & $\begin{array}{l}\text { Evidenciada na delimitação do } \\
\text { artefato (computador e algoritmos } \\
\text { para computador) nos OA. }\end{array}$ & $\begin{array}{l}\text { Demonstrada quando se propõe } \\
\text { que a avaliação de vantagens e } \\
\text { desvantagens seja produzida por } \\
\text { instrumentos já determinados } \\
\text { (algoritmos). }\end{array}$ & $\begin{array}{l}\text { Evidente na determinação de } \\
\text { instrumentos próprios dos algoritmos } \\
\text { como passos básicos para a resolução } \\
\text { de problemas. }\end{array}$ \\
\hline Linearidade & $\begin{array}{l}\text { Enfatiza-se na delimitação } \\
\text { temporal imposta para as } \\
\text { aprendizagens relativas aos } O A \\
\text { e na sequência de atividades } \\
\text { que confluem para o uso da } \\
\text { computação como algo mais } \\
\text { avançado em detrimento de } \\
\text { outros métodos de aprendizagem. }\end{array}$ & $\begin{array}{l}\text { Ressaltada na proposição de } \\
\text { OA que podem ser executados } \\
\text { apenas em ciclos mais avançados } \\
\text { (final do Ensino Fundamental e } \\
\text { Médio), evidenciando uma linha } \\
\text { unidirecional de aprendizagem. }\end{array}$ & $\begin{array}{l}\text { A resolução de problemas por } \\
\text { algoritmos no contexto educacional } \\
\text { se sobressai e não deixa evidente que } \\
\text { esta é uma das diferentes formas de } \\
\text { aprendizagem de conteúdos (e não } \\
\text { a finalidade da escola). }\end{array}$ \\
\hline Instrumentalismo & $\begin{array}{l}\text { Evidente no discurso de uso } \\
\text { de recursos tecnológicos de } \\
\text { determinado tipo (algoritmos) } \\
\text { como forma de resolver } \\
\text { problemas. }\end{array}$ & $\begin{array}{l}\text { Algoritmos como procedimento } \\
\text { e instrumento de resolução } \\
\text { de problemas comumente } \\
\text { solucionados por outras vias que } \\
\text { não são assumidas de maneira } \\
\text { explícita no texto. }\end{array}$ & $\begin{array}{l}\text { Se sobressai na ênfase ao método. } \\
\text { Os problemas a serem solucionados } \\
\text { é que representam os conhecimentos } \\
\text { formais, sendo a tecnologia um } \\
\text { instrumento de facilitação desse } \\
\text { processo. }\end{array}$ \\
\hline Neutralidade & \multicolumn{3}{|c|}{$\begin{array}{l}\text { Evidenciada na perspectiva de que os artefatos digitais representam um passo adiante nas aprendizagens } \\
\text { dos estudantes, não estimulando o diálogo com outras culturas, formas de aprender e resolver problemas } \\
\text { por meio de diversas técnicas e tecnologias. }\end{array}$} \\
\hline $\begin{array}{l}\text { Visão crítica da } \\
\text { tecnologia }\end{array}$ & \multicolumn{3}{|c|}{ No texto analisado, não foram observados elementos que respondessem aos parâmetros desta categoria. } \\
\hline
\end{tabular}

Fonte: elaborado pelas autoras.

\section{Conclusão}

A análise de conteúdo, realizada de acordo com a metodologia de Bardin (1977), produzida em relação à Cultura Digital no âmbito da BNCC (BRASIL, 2017a) revelou aspectos de Determinismo Tecnológico (FEENBERG, 2013) expressados nos Objetivos de Aprendizagem da subdimensão Domínio de Algoritmos, bem como na estrutura do documento como um todo. Esses aspectos foram evidenciados em quatro categorias: Determinação pelo artefato, Linearidad, Instrumentalismo, e Neutralidade. 
A categoria Visão Crítica da Tecnologia não foi observada em nenhum dos Objetivos de Aprendizagem analisados neste trabalho. Contudo, este aspecto pode estar presente em outros pontos do documento analisado, abrindo assim espaço para que esta análise seja complementada em estudos futuros.

Concluiu-se que, no contexto desta análise, um novo entendimento deve ser dado à Competência Cultura Digital na BNCC, a partir de uma visão crítica da tecnologia, segundo a qual a Tecnologia deixa de ser uma coleção de artefatos e técnicas para ser então percebida como um objeto desenhado e situado social e culturalmente, carregado de valores desde a sua concepção, sendo influenciado e influenciando as pessoas em diversas formas de interação (FEENBERG, 2013).

Entendeu-se ainda que as Competências da BNCC, dentre as quais se situa a Cultura Digital, não devem servir apenas como uma forma de ajustamento do educando a um modelo socioeconômico neoliberal, ensinando tarefas e temas contemporâneos que visam a manter o sujeito adaptado à sociedade conforme ela se apresenta. Longe disso, as Competências podem ser o pano de fundo onde se costuram conhecimentos e aprendizagens que atendem aos propósitos imediatos dos sujeitos e, ao mesmo tempo, onde se desenham novos mecanismos que permitam aos educandos a transformação do tecido social e cultural (SAVIANI, 2012b).

O que se propõe ao analisar criticamente a Competência Cultura Digital na BNCC não é sua exclusão das práticas pedagógicas e curriculares, em razão de que as tecnologias digitais constituem uma base técnica necessária para o desenvolvimento cultural e social dos educandos (SAVIANI, 2012b). Propõe-se, em lugar disso, que o estabelecimento de diretrizes para uso de tecnologias digitais seja amplamente discutido por todas as pessoas diretamente envolvidas no processo pedagógico de forma mais participativa, dando a elas oportunidade de se manifestar de diferentes formas e em diferentes momentos do desenho desse projeto. Tais diálogos, considerados imprescindíveis a partir desta análise, devem ser ainda sucedidos de mudanças radicais, no sentido da radicalização freiriana: uma opção consciente, crítica e passível de ser questionada a qualquer tempo (FREIRE, 1994).

O envolvimento de cada pessoa interessada da comunidade escolar desde os primeiros momentos da concepção desses códigos técnicos é importante, mas também se destaca que essa participação deve ser estimulada e acolhida ao longo de todo o processo de desenvolvimento das práticas pedagógicas. Com isso, acredita-se que é possível tornar o acesso e o uso das tecnologias digitais propostas pela BNCC verdadeiramente apropriadas aos múltiplos contextos onde se inserem - trabalhando com as pessoas da Educação, sobretudo os estudantes, e não sobre elas e suas necessidades (FREIRE, 1994).

\section{Referências}

BARDIN, L. Análise de conteúdo. São Paulo: Edições 70, 1977.

BRASIL. Lei no 9.131, de 24 de novembro de 1995. Altera dispositivos da lei no 4.024, de 20 de dezembro de 1961, e dá outras providências. Brasília: Presidência da República, 1995. Disponível em: https://cutt.ly/umEICiN. Acesso em: 7 abr. 2020.

BRASIL. Lei no 9.394, de 20 de dezembro de 1996. Estabelece as diretrizes e bases da educação nacional. Brasília: Presidência da República, 1996. Disponível em: https://cutt.ly/0mEl1cK. Acesso em: 3 abr. 2020. 
BRASIL. Ministério da Educação. Base nacional comum curricular: educação é a base. Brasília: MEC, 2017a. Disponível em: http://basenacionalcomum.mec.gov.br/abase/. Acesso em: 2 abr. 2020.

BRASIL. Ministério da Educação. Conselho Nacional de Educação. Parecer CNE/CP 15/2017. Brasília: MEC, 2017b. Disponível em: https://cutt.ly/8mvO1X0. Acesso em: 27 mar. 2020.

BRASIL. Ministério da Educação. Base nacional comum curricular: histórico. Disponível em: http:// basenacionalcomum.mec.gov.br/historico. Acesso em: 28 mar. 2020.

FEENBERG, A. Critical theory of technology and STS. Thesis Eleven, Melbourne, v. 138, n. 1, p. 3-12, 2017. DOI: https://doi.org/10.1177/0725513616689388.

FEENBERG, A. Questioning technology. London: Routledge, 1999.

FEENBERG, A. Racionalização subversiva: tecnologia, poder e democracia. In: NEDER, R. T. (org.). A teoria crítica de Andrew Feenberg: racionalização democrática, poder e tecnologia. 2. ed. Brasília: Observatório do Movimento pela Tecnologia Social na América Latina, 2013. p. 67-96.

FREIRE, P. Educação como prática da liberdade. São Paulo: Paz e Terra, 1994.

FREIRE, P. Pedagogia da autonomia: saberes necessários à prática educativa. 25. ed. São Paulo: Paz e Terra, 2002.

KUENZER, A. Z. Exclusão includente e inclusão excludente: a nova forma de dualidade estrutural que objetiva as novas relações entre educação e trabalho. In: LOMBARDI, J. C.; SAVIANI, D.; SANFELICE, J. L. (org.). Capitalismo, trabalho e educação. 3. ed. São Paulo: Autores Associados, 2002. p. 77-96.

PERRENOUD, P. Construir competências é virar as costas aos saberes? Pátio: revista pedagógica, Porto Alegre, n. 11, p. 15-19, nov. 1999. Disponível em: https://cutt.ly/jmvSNUL. Acesso em: 1 abr. 2020.

SAVIANI, D. Escola e democracia. 42. ed. Campinas: Autores Associados, 2012a.

SAVIANI, D. Marxismo, educação e pedagogia. In: SAVIANI, D.; DUARTE, N. (org). Pedagogia histórico-crítica e luta de classes na educação escolar. Campinas: Autores Associados, 2012b. p. 5985. 